\title{
An index to evaluate the wear resistance of the electrode in micro-EDM
}

\author{
Yao-Yang Tsai ${ }^{\mathrm{a}, *}$, Takahisa Masuzawa ${ }^{\mathrm{b}}$

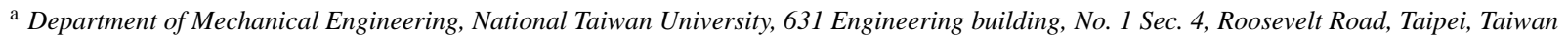 \\ ${ }^{\mathrm{b}}$ Institute of Industrial Science, University of Tokyo, Tokyo, Japan
}

\begin{abstract}
The EDM is very complex including plasma formation in the dielectric, interaction between electrons and thermal ions, and heat transfer. It has been known that the mechanism of material removal in EDM is based on electrical energy transfer and thermal process. However, energy transfer from electric energy into thermal energy is still an unknown topic, particularly in micro-EDM using small energy ( $<100 \mu \mathrm{J})$. In this study, the effects of thermal properties on electrode wear were investigated. It was evident that the boiling point of the electrode material plays an important role in the wear mechanism of micro-EDM. Therefore, the boiling point cannot be negligible in considering the wear resistance of the electrode material. A proposal is to introduce a new function where the latent heats are taken into account as a modified type of the temperatures. The experimental data obtained in micro-EDM performance shows strong correlation with this new index.
\end{abstract}

(C) 2004 Elsevier B.V. All rights reserved.

Keywords: Micro-EDM; Electrode wear; Wear resistance; Thermal properties

\section{Introduction}

Miniaturization is an important trend and is required in a wide range of industrial production. Such products will supply the merits such as light, portable, compact multi-functional, less material consumption, and low cost. EDM (electrical discharge machining) is an interesting way to realize micromachining process for the production of three-dimensional complex microcomponents and microstructures from metallic substrate and semiconductor substrate [1,2]. As EDM is a thermal process employing electric-thermal energy to remove material from the selected areas. As the force between the electrode and the workpiece can be negligible, the error caused by the tool deformation is almost zero. The capability of machining a microhole and a microshaft as small as $5 \mu \mathrm{m}$ in diameter and surface roughness $\left(R_{\max }\right)$ better than $0.1 \mu \mathrm{m}$ is already reported [3]. Furthermore, this non-contact technique can make the various and complex microstructures by using a precise mechanism providing sub-micrometers of accuracy $[4,5]$.

However, electrode wear occurs during EDM process leading to a lack of machining accuracy in the geometry of workpiece. To reduce the influence of the electrode wear, it

\footnotetext{
* Corresponding author. Tel.: +886-2-23654602; fax: +886-2-23631755.

E-mail addresses: yytsai@research.ntu.edu.tw (Y.-Y. Tsai), masuzawa@iis.u-tokyo.ac.jp (T. Masuzawa).
}

is necessary either to feed electrode larger than the workpiece thickness in the case of making through-holes, or to prepare several electrodes for roughing and finishing in the present state of technology. For three-dimensional cavities, ED scanning [6] or uniform wear method [5] was applied by using small diameter electrode and forward-back tool path. However, tool life is still another concerned problem.

Micro-EDM is the application of EDM on microfield. The low energy range is becoming important when the EDM process is used into microfield. However, little is known of the electrode wear in low energy range applied in micro-EDM. In this study, the small electrode wear including shape change of the electrode was carefully measured by means of scanning electron microscope (SEM). Furthermore, the wear characteristics are associated with material properties and a new index to evaluate wear resistance of the electrode is recommended.

\section{Experiments and measurement method}

Wear ratio is defined as the ratio of amount of electrode removal to the amount of workpiece removal. There are four methods to evaluate electrode wear ratio by means of measuring weight, shape, length, and total volume, respectively. A well-recognized one is by calculating volumetric wear ratio $(v)$. In fact, it is usual to measure the weight differences and transfer them into the volumes by the density of materi- 


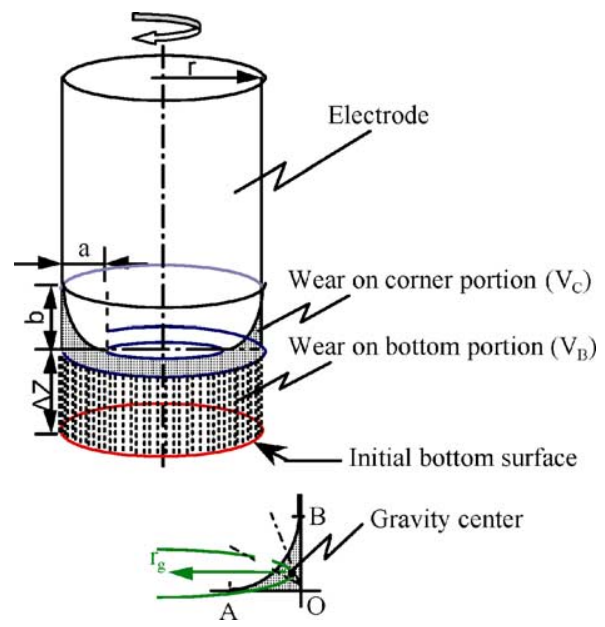

Fig. 1. Wear volume of the electrode.

als. However, this method is unsuitable for micro-EDM because the weight change of the materials is so small (about less than $10 \mathrm{ng}$ ) that it is not easy to measure it accurately. Therefore, it is essential to measure and analyze removed volume directly.

To simplify the measurement of the removed volume, making through-holes were performed by using rotating cylindrical electrodes. The worn volume of the electrode can be divided into two portions, corresponding to the change of electrode length and corner rounding as illustrated in Fig. 1. The wear volumes on bottom portion $\left(V_{\mathrm{B}}\right)$ and corner portion $\left(V_{\mathrm{C}}\right)$ are assumed to be the volume of a cylinder and of a revolution body, respectively, because a rotating tool electrode is used during machining. The wear on bottom portion $V_{\mathrm{B}}$ was calculated from the cross-sectional area of an electrode and the wear length (the difference of the position of an electrode's tip between before and after machining). Thus, $V_{\mathrm{B}}=\pi r^{2} \Delta Z$. Here $\Delta \mathrm{Z}$ can be measured on machine by electrical contact at a reference point on the workpiece with a tester or buzzer, etc. The radius of the electrode $(r)$ is measured by an optical microscope with $0.1 \mu \mathrm{m}$ of resolution.

Wear volume on corner portion $V_{\mathrm{C}}=$ area $\mathrm{OAB} \times 2 r_{\mathrm{g}}$. Area $\mathrm{OAB}$ can be calculated easily by integrating if curve $\mathrm{AB}$ is known. However, it is very difficult to measure the curvature radius of corner portion directly and accurately since both the tangent points A, B and the center of curve are unknown. In order to decide the wear curve on corner portion, one has to give a close interval for this curve in the SEM photos. According to Weierstrass' polynomial approximation theorem [7], any real continuous function (curve) on the closed interval can be described by a sequence of polynomials $Y(x)$. There exists for any $\varepsilon>0$ and $\delta>0$ such that

$$
\left|Y(x)-Y\left(x^{\prime}\right)\right|<\varepsilon, \quad \text { whenever }\left|x-x^{\prime}\right|<\delta
$$

Therefore, curve $\mathrm{AB}$ could be estimated based on geometric relations from intersection points with some known straight lines. First, orthogonal extended tangent lines $\mathrm{OA}$ and $\mathrm{OB}$
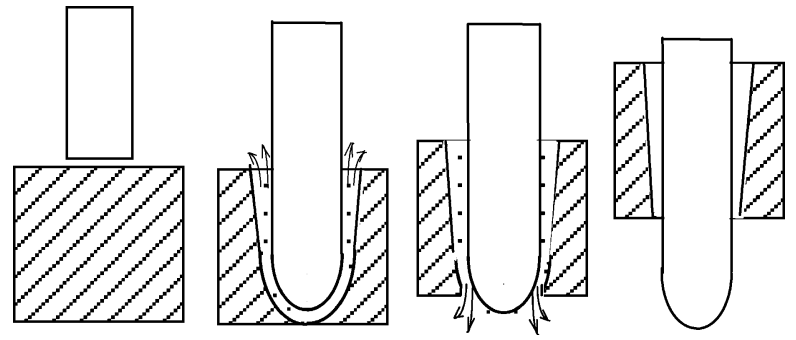

Fig. 2. Influence of electrode feed on the shape of a hole.

from the edges of an electrode were drawn and an orthogonal coordinate was established in the enlarged picture of corner wear portion. Next is to give two known lines such as $30^{\circ}$ and $60^{\circ}$ angular lines in Fig. 1, and then the intersection points $\mathrm{P} 1$ and $\mathrm{P} 2$ could be easily obtained. The curve of corner wear will be estimated from interval P1 and P2.

The $n$ power polynomial of curve function $Y(x)$ is determined by $n=\ln \left(y_{2}-y_{1}\right) / \ln \left(x_{2}-x_{1}\right)$. In general, curve AB is regarded as a part of quadratic curve such as ellipse (including circle), parabola line or hyperbola line [8]. Once the curve of corner wear is obtained finally, one can get easily the required data, such as the length $\mathrm{OA}$, area $\mathrm{OAB}$ and the position of gravity center. Since the wear at the center part is separate, the wear at corner portion $V_{\mathrm{C}}$ considered as the revolution body, can be calculated by longitudinal cross-section area $\times$ revolution circumference, where the revolution circumference is supposed to be the circumference from the gravity center of longitudinal cross-section area to rotation center $\left(2 \pi r_{\mathrm{g}}\right)$. Then, $V_{\mathrm{C}}=$ area $\mathrm{OAB} \times 2 \pi r_{\mathrm{g}}$.

Although, the machined shape of the workpiece is the reverse-copied shape of the electrode also in micro-EDM, there is a restriction from measurement difficulty of small dimension. A simple cylindrical electrode is used, and one-dimensional machining (making hole) is carried out to evaluate wear in the experiments. It is still reliable and useful because volumetric wear ratio does not depend on machining path. However, the shapes of the machined holes were not confirmed as the result of electrode wear if electrode does not feed enough. Fig. 2 shows the relationship of the hole shape with feed of an electrode. In order to obtain stable machined holes, it is important to feed electrodes

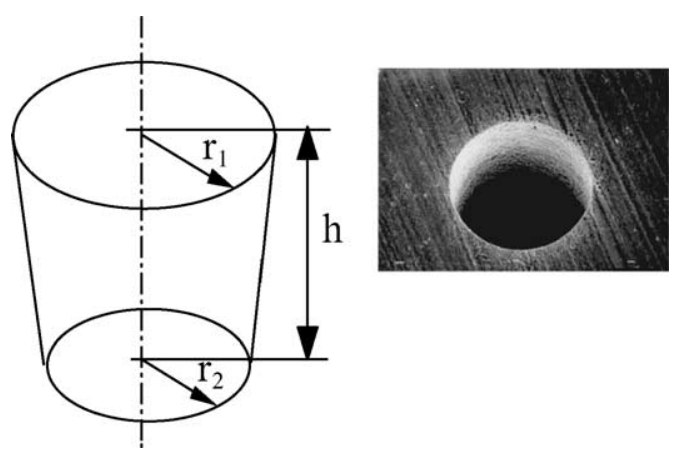

Fig. 3. Volume of the machined microhole. 


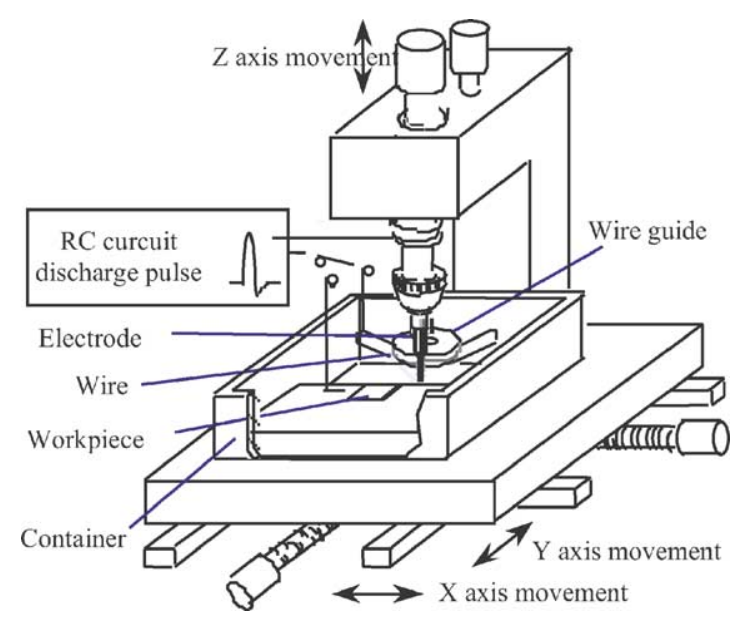

Fig. 4. Experimental configuration.

several times as long as thickness of a workpiece. In practice, an electrode is fed $300 \mu \mathrm{m}$ long for $100 \mu \mathrm{m}$ thickness of a workpiece.

Due to debris moving and the second discharge on the side of hole, the machined hole is not an ideal cylindrical one but a tapered one as shown in Fig. 3. The removal volume of workpiece $\left(V_{\mathrm{W}}\right)$ was calculated from the entrance and exit radii $\left(r_{1}, r_{2}\right) V_{\mathrm{W}}=\pi / 3\left(r_{1}^{2}+r_{1} r_{2}+r_{2}^{2}\right) h$, where $h$ is the thickness of workpiece.

Experiments were carried out in a micro-EDM machine that was setup in the author's laboratory. Fig. 4 shows its configuration. The electrode positioning was controlled within $1 \mu \mathrm{m}$. In micro-EDM, it is necessary to supply small discharge energy because of small unit removal. RC circuit generator is the easiest to satisfy such requirements for pulse generations of micro-EDM. The polarity of the tool electrode was connected with the negative terminal of power

Table 1

Experimental conditions

Experiment method

Making through-holes in EDM oil

Using rotating tool electrode

Polarity

Tool electrode: negative Workpiece: positive

Electric condition

Open circuit voltage $=100 \mathrm{~V}$

Discharge capacitance $=100 \mathrm{pF}$

Charging resistance $=1 \mathrm{k} \Omega$

Average discharge current $=1 \mathrm{~mA}$

Feed

$300 \mu \mathrm{m}$ in the $Z$-axis

Workpiece

$100 \mu \mathrm{m}$ thick plate

Electrode

$\varnothing 50 \mu \mathrm{m}$, length $500 \mu \mathrm{m}$, fabricated by WEDG

Straightness: within $\pm 1 \mu \mathrm{m}$ overall length

Experimental parameters supply during hole-making process. In order to decrease the stray capacitance parallel to the discharge circuit, charging resistances are connected near to the capacitor. The lead cables in the discharge circuit are vinyl chloride coated copper wires of about $18 \mathrm{~cm}$ in total length to reduce the influence of inductance due to cable.

All tool electrodes were fabricated to a $\varnothing 50 \mu \mathrm{m}$ cylindrical microelectrode with $500 \mu \mathrm{m}$ length and $\pm 1 \mu \mathrm{m}$ straightness by wire electrodischarge grinding (WEDG) [9] before making hole experiments. The workpieces were $100 \mu \mathrm{m}$ thick plates throughout experiments. Making through-holes were carried out on a single $100 \mu \mathrm{m}$ thick workpiece to investigate the electrode wear. Stainless steel 304 is commonly used on micro-parts is as a workpiece, with comparison of the difference in the workpiece, such as pure copper $(99.99 \%)$ and pure iron (99.95\%). The commercial work fluid for EDM was used as dielectric (made by Mitsui Co. EDS). Machining conditions used in this paper are shown in Table 1.

\section{Experimental result and discussion}

\subsection{Effect on wear ratio}

The volumetric wear ratios $(v)$ of various electrode materials were experimentally investigated. The results are as shown in Fig. 5. The wear of tungsten electrode is the smallest among tested materials because its melting and boiling points are the highest. Wear of aluminum is the largest among the experimental materials due to the lowest melting point. Besides, the wears of copper and silver electrodes are smaller than iron or nickel electrode although having lower melting points and boiling points. It seems to relate with the excellent thermal conductivity of copper and silver.

Fig. 6 shows the relationship between the electrode diameter and the volumetric wear ratio $(v)$ when tungsten, molybdenum, copper and iron were used as electrode materials. From experimental result, we know the magnitude of $v$ is in order of electrode $\mathrm{Fe}>\mathrm{Cu}>\mathrm{Mo}>\mathrm{W}$. Tungsten electrode

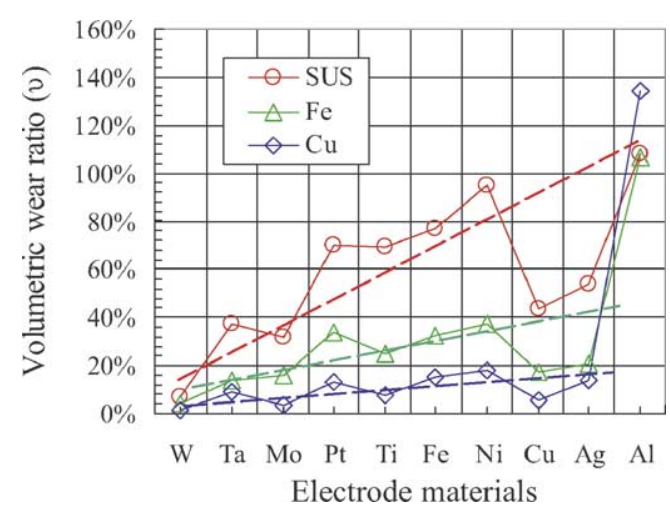

Fig. 5. Volumetric wear ratio of various electrode materials (in order of the melting point $\rightarrow$ small). 


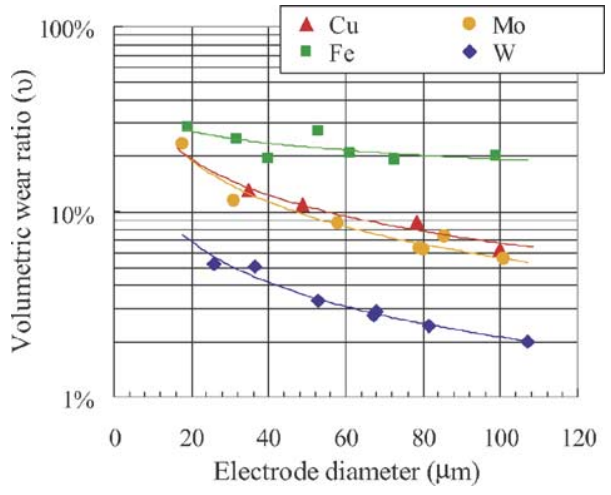

Fig. 6. Relationship between the size effect of material and electrode wear.

with high thermal capability has excellent wear resistance. Next are molybdenum and copper electrodes, the former has high melting point but the latter has excellent thermal conductivity. As to the size effect, it is clear that the volumetric wear ratio $v$ is increased as the electrode diameter is decreased whichever electrode material is.

\subsection{Effects on wear morphology}

The wear morphologies of the machined electrodes, after making holes on the workpiece SUS304 under the same condition, are shown in Fig. 7. It was found that strong wear appears on the corner portion especially for iron (Fe), nickel (Ni), and titanium ( $\mathrm{Ti}$ ) electrodes with the low thermal conductivity. Electrode of aluminum ( $\mathrm{Al}$ ) shows the trace of melting while SUS304 as a workpiece. Bending was also seen when wokpiece was iron. The very low melting point of $\mathrm{Al}$ electrode has to be taken into account. From these experimental results, we know corner rounding of electrode is correlated strongly with heat. A great amount of heat stacked at the corner would cause strong wear off. Fig. 8 shows the relationship between volumetric wear ratio on corner portion and temperature diffusivity. Temperature diffusivity $(\alpha)=$ $\lambda / \rho c$, where $\lambda$ is the thermal conductivity, $\rho$ the density and $c$ the specific heat.

\subsection{Evaluation function for electrode material}

$\lambda T_{\mathrm{m}}$ has been widely used as an effective measure of wear resistance of electrode material. However, the experimental results did not fit this evaluation curve as shown in Fig. 9. It may be caused by the surface temperature over boiling point of material as the result of very high energy density when energy flows into very small discharge spot in micro-EDM.

Heuvelman [10] pointed out the importance of the electrode material and the pulse duration from the model es-

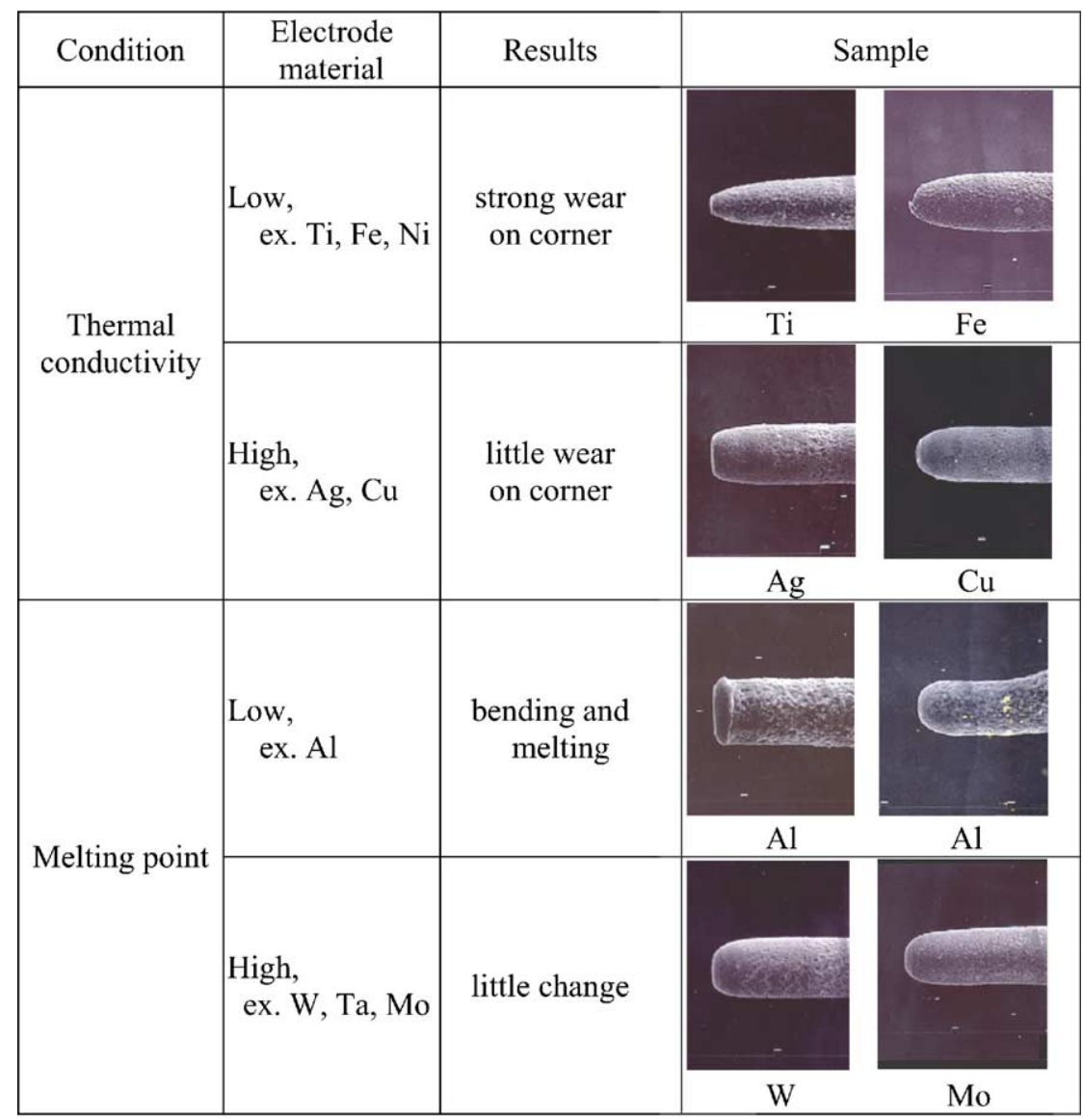

Fig. 7. Electrode morphology with the thermal properties of materials. 


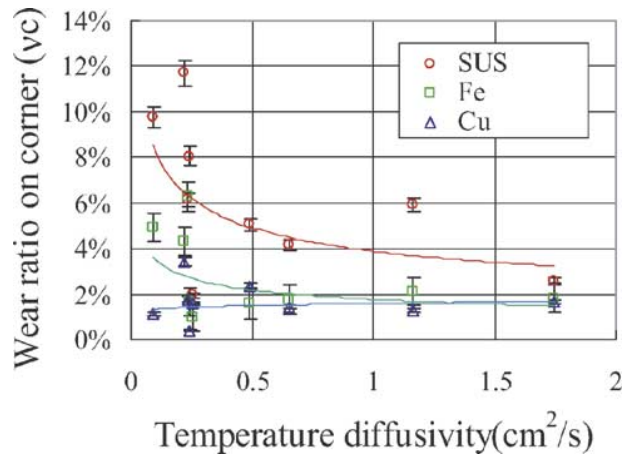

Fig. 8. Corner wear and temperature diffusivity.

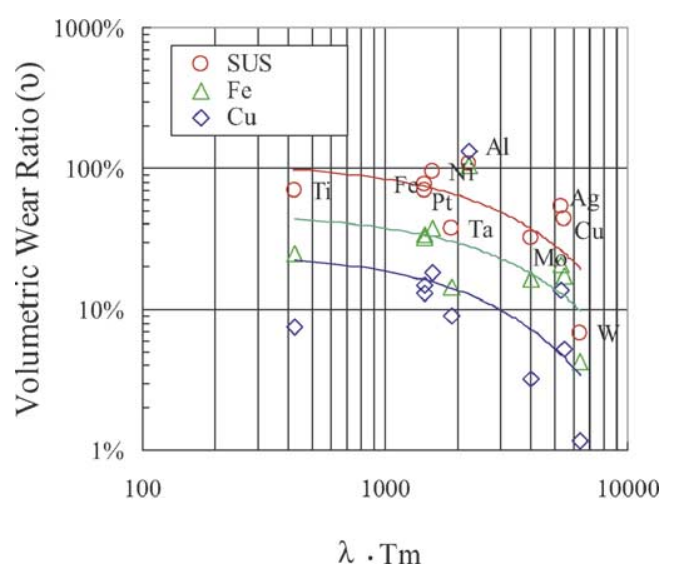

Fig. 9. Relationship of the volumetric wear ratio with thermal properties $\left(\lambda T_{\mathrm{m}}\right)$ of the electrode.

tablished by Leemries. He proposed $\lambda \rho c T_{\mathrm{m}} c^{2}$ for calculation of the time for maximum melting of arbitrary material, which he called erosion strength. High erosion strength is desired for tool material. High erosion strength means a high flux of power intensity is necessary and more difficult to erode. In the case of micro-EDM, owing to very small discharge spot, very high energy density is essential for material removal. Therefore, boiling would play an important role in wear mechanism of micro-EDM. In order to extend the calculation over the melting point, the melting point $\left(T_{\mathrm{m}}\right)$ and the boiling point $\left(T_{\mathrm{b}}\right)$ are modified, taking latent heats into account, respectively. $T_{\mathrm{mc}}=T_{\mathrm{c}}+h_{\mathrm{m}} /(\rho c)$, $T_{\mathrm{bc}}=T_{\mathrm{b}}+\left(h_{\mathrm{m}}+h_{\mathrm{v}}\right) /(\rho c)$; where, $h_{\mathrm{m}}$ is the fusion latent heat, and $h_{\mathrm{v}}$ the evaporation latent heat. Fig. 10 plots the data obtained in this study as the relationship between the new index $\lambda \rho c T_{\mathrm{mc}} T_{\mathrm{bc}}$ and volumetric wear ratio $(v)$ of various electrode materials. It shows stronger correlation between the two parameters compared with the relationship using the index $\lambda T_{\mathrm{m}}$ (compared to Fig. 9).

Another advantage of material with high boiling point was found. High boiling point allows a higher possible temperature at the cathode, leading to easier electron emission. This is effective to increase the ratio of the electronic current to the total current. As a result, the energy distribution to the cathode can be decreased.

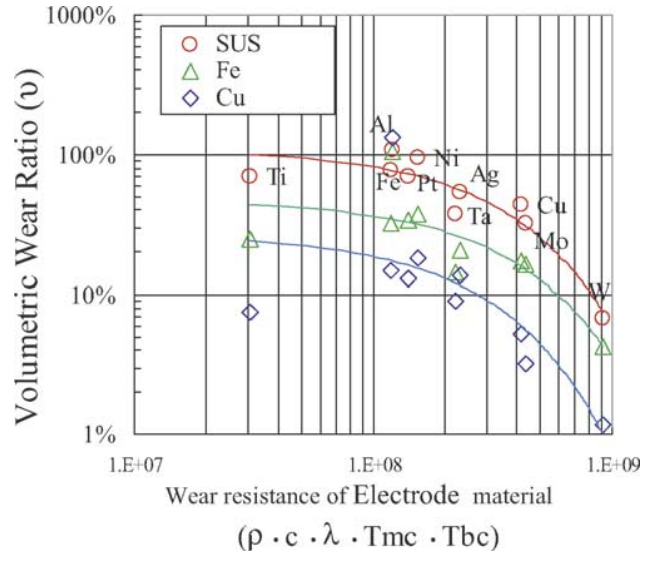

Fig. 10. Relationship of the volumetric wear ratio with the index $\lambda \rho c T_{\mathrm{mc}} T_{\mathrm{bc}}$ considering latent heats and boiling point.

\section{Summary}

In this study, the electrode wears of various materials in micro-EDM were experimentally investigated and analyzed. The main conclusions obtained in this study are as follows:

- The volumetric wear ratio of the electrode becomes small for the electrode material with high boiling point, high melting point, and high thermal conductivity. This tendency is independent of the workpiece materials.

- Corner wear of electrode relates to diffusion of heat. The corner rounding is more obvious when the thermal conductivity of the electrode is low.

- The boiling point of the electrode material plays an important role in wear mechanism of micro-EDM, since high surface temperature and high energy density correspond to small discharge spot. An index was proposed to include the boiling phenomenon into the evaluation of electrode performance. The index is $\lambda \rho c T_{\mathrm{mc}} T_{\mathrm{bc}}$ for evaluating the erosion property of electrode material in micro-EDM. Here, the latent heats are taken into account in a modified type of temperature.

\section{References}

[1] D. Reynaerts, P.-H. Heeren, H. Brussel, Microstructures of silicon by electro-discharge machining (EDM). Part II. Application, Sens. Actuators A 61 (1997) 379-386.

[2] D. Reynaerts, W. Meeusen, H. Brussel, Machining of threedimensional microstructures in silicon by electrodischarge machining, Sens. Actuators A 67 (1998) 159-165.

[3] T. Masuzawa, State of the art of micromachining, Ann. CIRP 49 (2) (2000) 473-488.

[4] K.P. Rajurkar, Z. Yu, 3D micro-EDM using CAD/CAM, Ann. CIRP 49 (1) (2000) 127-130.

[5] Z. Yu, T. Masuzawa, M. Fujino, Micro-EDM for three-dimensional cavities-development of uniform wear method, Ann. CIRP 47 (1) (1998) 169-172.

[6] N. Tomimoto, T. Magara, T. Yuzawa, N. Watanabe, Micro electric discharge scanning technology, J. Jpn. Soc. Prec. Eng. 64 (12) (1998) 1727-1730 (in Japenese). 
[7] K. Yosida, Functional Analysis, 6th ed., Springer, New York, 1980, pp. 8-12.

[8] Y.-Y. Tsai, T. Masuzawa, M. Fujino, The wear of electrode in micro-EDM, in: Proceedings of the Annual Assembly of JSEME, 1998, pp. 135-136 (in Japanese).
[9] T. Masuzawa, K. Kobayashi, M. Fujino, T. Suzuki, Wire electrodischarge grinding for micromachining, Ann. CIRP 34 (1) (1985) 431434.

[10] C.J. Heuvelman, Some aspects of the research on electro-erosion machining, Ann. CIRP 17 (1969) 195-199. 